\title{
Method for improving performance of devices for adjustable reactive power compensation
}

\author{
Vasiliy Cheremisin ${ }^{1}$ and Andrey Nikonov ${ }^{1, *}$ \\ ${ }^{1}$ Omsk State Transport University (OSTU), 644046, Omsk, Russia
}

\begin{abstract}
Annotation. The article presents a method for selecting the parameters of the current-voltage characteristics of adjustable reactive power compensation devices used at sectioning stations of railway sections electrified by alternating current with a voltage of $27.5 \mathrm{kV}$. This technique is based on the experience of operating two types of devices in the traction power supply system. Power control of these devices is implemented by the voltage level at the switching point. Selection of the setpoint voltage and slope characteristics was done. The developed method allows increasing the efficiency of devices by eliminating the voltage losses on the active component of traction loads. That will reduce the loss of electricity in the system of traction power supply. Changing the parameters of the characteristics will increase the relationship between the reactive power consumed in the zone and the voltage measured by the devices. Following the results of the formation of the methodology, an example of the choice of characteristics for a real compensation device is presented.
\end{abstract}

\section{Introduction}

The annual increase in freight traffic leads to the appearance of restrictions on the part of the traction power supply system. At a number of interstation stations, with the existing movement sizes and masses of trains, the operating modes of the traction power supply devices are close or have reached the limit. In order to solve this problem, in areas electrified with alternating current, continuously adjustable devices of transverse reactive power compensation are used.Two types of devices are in operation: static thyristor compensators FCC-TCR and static reactive power generators STATCOM (Fig.1). In general, the FCC-TCR and STATCOM are used in external power supply systems and the issues of controlling these devices in the conditions of railway transport are not considered. [1- 4].

The greatest effect of the device is the compensation of reactive power directly at the consumer (electric rolling stock(EPS), in the traction network such a point is the partition post.They do not install directly on electric locomotives due to the fact that most of the timeelectric rolling stock are out of work. In addition to increasing the voltage level, controllable VAR generator are used to: reduce power losses in the traction network, reduce

\footnotetext{
*AndrewNikonov671@gmail.com
} 
the reactive power factor to the normalized value, filter the higher harmonic components of the load.

FCC-TCR circuit includes thyristor-reactor group (TCR) and filter compensating circuit (FCC). TCR is a continuously adjustable source of inductive reactive power, and the FCC is a source of reactive power of a capacitive nature and a filter of higher harmonics tuned to the frequency of the third harmonic. TCR consists of a high-voltage thyristor key, $V S$, and a reactor $L_{2}$. FCC consists of a filter reactor $\mathrm{L} 1$ and the capacitor Bank $C$. TCR current is regulated by thyristor key by changing the angle of ignition $\alpha$. The reactive power $Q$ FCCTCR is determined from the following system of equations, quar:

$$
\left.\begin{array}{l}
Q=Q_{F C C}-Q_{T C R} \\
Q_{F C C}=U_{n} \cdot I_{F C C} \\
Q_{F C C}=U_{n} \cdot I_{T C R}(\alpha) \\
I_{T C R}(\alpha)=\frac{U_{n}}{\omega \cdot L} \cdot\left(1-\frac{2}{\pi} \cdot \alpha-\frac{1}{\pi} \cdot \sin 2 \alpha\right)
\end{array}\right\},
$$

where $Q_{F C C}-$ reactive power FCC, kvar; $Q_{T C R}$ - reactive power TCR, kvar; $I_{F C C}-$ the current in the circuit FCC, A; $I_{\mathrm{TCR}}-\mathrm{TCR}$ reactor circuit current, A, $\alpha$ - the opening angle of the thyristors, the degree.
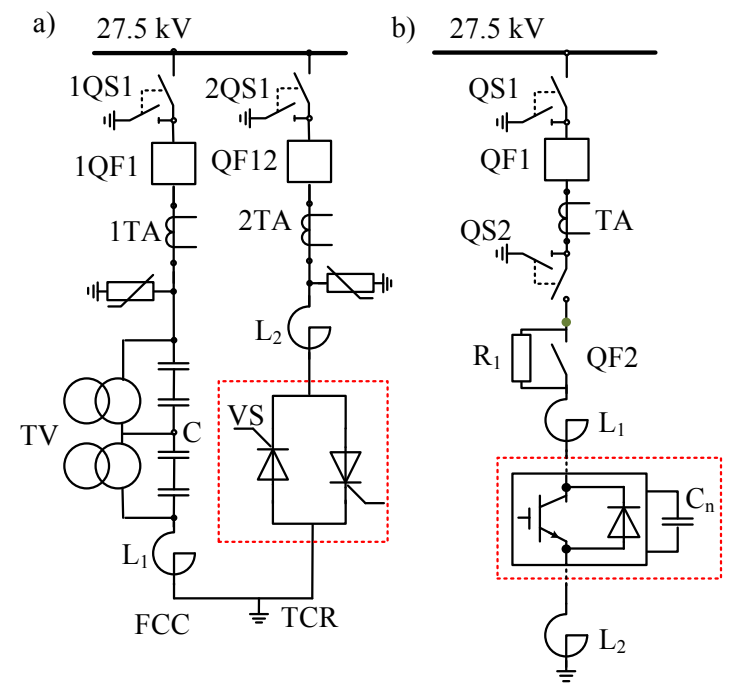

Fig. 1. Schematic construction a) FCC-TCR, b) STATCOM

STATCOM is a device based on a static voltage converter. Its capacitive or inductive output current can vary independently of the mains voltage. The power part of STATCOM is based on bipolar IGBT transistors. In fact, it is a multi-level inverter consisting of 28 power H-bridge modules connected in series (Fig. 2). The voltage at its output consists of the voltages of the individual modules. Each individual output voltage of the module is formed by controlling the moments of unlocking and locking of the transistors with the help of pulse-width. The total output voltage is the sum of the output voltages of the individual H-bridge modules. Connection to the traction network is made through smoothing current filters [5-7]. The reactive power generated by STATCOM is determined from the following formula, kvar: 


$$
Q_{\text {STATCOM }}=\frac{U_{n} \cdot\left(U_{n}-U_{s t}\right) \cdot \cos \delta}{X},
$$

where $U_{n}$ - the rated voltage in the contact network; $k V ; U_{s t}$ - voltage at the output STATCOM, $\mathrm{kV} ; \delta$ - the angle between the voltage STATCOM and the voltage in the contact network, deg. $X$ - reactance of STATCOM reactors, Ohm.

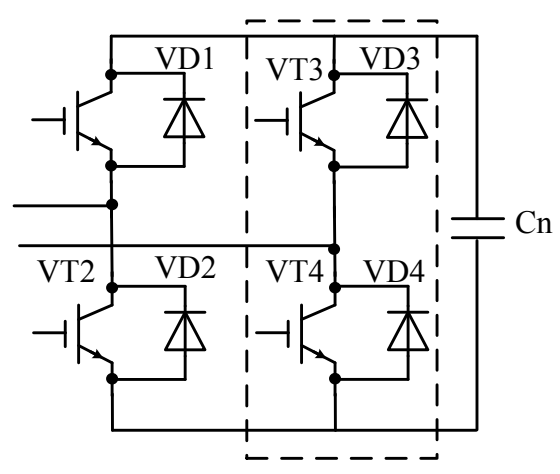

Fig. 2. Power module STATCOM

FCC-TCR circuit includes thyristor-reactor group (TCR) and filter compensating circuit (FCC). TCR is a continuously adjustable source of inductive reactive power, and the FCC is a source of reactive power of a capacitive nature and a filter of higher harmonics tuned to the frequency of the third harmonic. TCR consists of a high-voltage thyristor key, $V S$, and a reactor $L_{2}$. FCC consists of a filter reactor $\mathrm{L} 1$ and the capacitor Bank $C$. TCR current is regulated by thyristor key by changing the angle of ignition $\alpha$. [8,9] The reactive power $Q$ FCC-TCR is determined from the following system of equations, quar:

$$
\left.\begin{array}{l}
Q=Q_{F C C}-Q_{T C R} \\
Q_{F C C}=U_{\mathrm{n}} \cdot I_{F C C} \\
Q_{F C C}=U_{\mathrm{n}} \cdot I_{T C R}(\alpha) \\
I_{T C R}(\alpha)=\frac{U_{n}}{\omega \cdot L} \cdot\left(1-\frac{2}{\pi} \cdot \alpha-\frac{1}{\pi} \cdot \sin 2 \alpha\right)
\end{array}\right\},
$$

where $Q_{F C C}-$ reactive power FCC, kvar; $Q_{T C R}$ - reactive power TCR, kvar; $I_{F C C}$ - the current in the circuit FCC, A; $I_{\mathrm{TCR}}$ - the current in the circuit TCR, A, $\alpha$ - the opening angle of the thyristors, the degree.

Operating conditions of VAR generator at the point of connection do not allow to provide availability of the reliable channel of information transfer of the values of the currents consumed on feeders of adjacent traction substations. In this regard, the VAR generator control algorithm is based on the comparison of the measured voltage value at the connection point with a given setpoint. Based on them, the generated reactive current required to stabilize the voltage at the level of this setpoint is calculated. The control algorithm for the voltage level at the point of connection does not allow to realize the full potential of the VAR generator. According to the results of experimental measurements, the correlation between the PS voltage and the reactive power consumed in the inter-substation zone is -0.78 . However, the availability of data on currents consumed by substation feeders will bring the correlation closer to 1 . When controlling the voltage level does not take into account: the influence of the active component of the traction load, voltage fluctuations in the external power supply system, the location of the EPS on the zone, etc. All this leads to 
overcompensation or under-compensation of reactive power, and, consequently, additional losses in the traction network.

To increase the efficiency of the VAR generator with the existing algorithm is possible by changing the parameters of the current-voltage characteristic.

The shape of the volt ampere characteristic is determined by two parameters: voltage setpoint and slope. The main difference between current-voltage characteristics are segments $A_{1} B O$ and $A_{1} O$ (Fig. 3). Here, the voltage is reduced due to the high load and the devices behave differently, the FCC-TCR current decreases in proportion to the voltage, and the STATCOM current stabilizes. It is this moment that determines the main advantage of STATCOM over FCC-TCR [10, 11].

In accordance with, the voltage level on the EPS current collector should not exceed 29 $\mathrm{kV}$. In this regard, the voltage on the tires traction substation is usually set in the range from 28.5 to $29 \mathrm{kV}$. In the absence of traction load, the loss of tension on the partitioning post tire will be negligible. It is determined only by the resistance of the traction network. Thus, the selection of the setpoint above the no-load current is invalid. Given the above, we can conclude about the relevance of the development of this method.

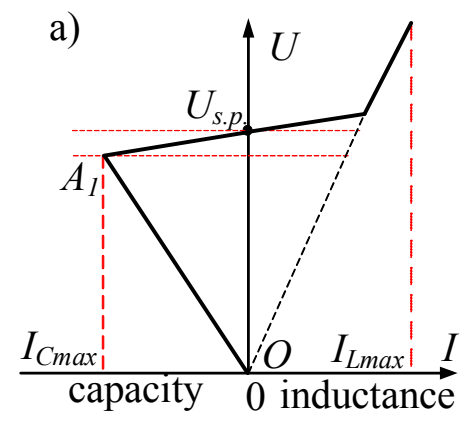

b)

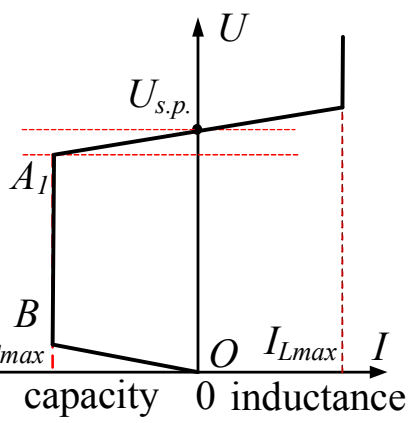

Fig. 3. Operating V-I area a) of the FCC-TCR; b) of the STATKOM

\section{Materials and methods}

The choice of the voltage setting is proposed to be based on the reduction of power consumption of the VAR Generation for its own needs, as well as reducing power losses in the main equipment of the devices. To do this, it is necessary to reduce the operating time of the devices, while providing a given train schedule. In FCC-TCR -generated current FCC is constant and does not depend on the setpoint voltage. To minimize power losses in the equipment and consumption for own needs is possible only by reducing the operating time of the TCR.

By selecting a voltage setting below the no-load voltage STATCOM (FCC-TCR, in cases where this function is implemented) will consume reactive power, reducing the voltage level to a predetermined. At the same time, losses in the traction network will increase. In this regard, the set point of the device is rational to choose equal to the idle voltage.

To improve the accuracy of the set point, it is proposed to obtain it by measuring at the switching point VAR generator for each inter-substation zone. This requires:

- make sure that during the measurements in the system of external and traction power supply are not carried out repairs and modes that may adversely affect the measurement results;

- make sure there are no trains in the inter-station zone;

- perform voltage measurement. 


\section{Results}

In practice, the horizontal volt ampere characteristics are rarely used. The main advantages of the inclined characteristic over the horizontal when installed in the traction power supply system are a decrease in the amplitude of the voltage fluctuation on the current collector of the rolling stock, an extension of the range of operation of the device. Also, the slope of the volt ampere characteristics allows for parallel operation of the two devices

Power loss in the traction network is proposed to reduce by reducing the overcompensation caused by the algorithm of the VAR generator. As is known, the voltage loss is determined by the reactive and active component of the traction load. The control system of the VAR generator does not distinguish these components and calculates the generated current, depending on the amount of these voltage losses. This leads to overcompensation and additional power losses in the traction network.

To exclude the influence of the active component of the traction load on the generated VAR generator current, the slope calculation method is presented below. Voltage losses at the inter-station zone are calculated by the formula, $\mathrm{V}$ :

$$
\Delta U=I_{n} \cdot(R \cdot \cos \varphi+X \cdot \sin \varphi),
$$

where $\Delta U$ - voltage losses in the area to the switching point, $\mathrm{V} ; I_{n}$ - traction load current, $A ; R$ - the resistance of the traction network, Ohm: $X$ - reactive resistance of traction network, Ohm; $\varphi$ - the angle between the traction current and the voltage in the contact network, degrees.

The active and reactive resistance of the traction network are determined from the expressions:

$$
\begin{aligned}
& R=l \cdot r_{t} ; \\
& X=l \cdot x_{t},
\end{aligned}
$$

where $r_{t}$ - specific resistance of traction network, Ohm / $\mathrm{km} ; x_{t}$ - specific reactive resistance of the traction network, Ohm $/ \mathrm{km} ; l$ - length of the section, $\mathrm{km}$.

According to the automated system of commercial accounting, the average value of the reactive power factor $\operatorname{tg} \varphi$ is 0.7 , therefore, $\varphi \approx 35^{\circ}$. $\mathrm{V}$ :

From formula (1) the loss of voltage on the reactive component of the traction load is,

$$
\Delta U_{r}=I_{n} \cdot X \cdot \sin \varphi
$$

Similarly, the voltage loss on the active component of the traction load, V:

$$
\Delta U_{a}=I_{n} \cdot R \cdot \cos \varphi \cdot
$$

Next, we calculate the ratio of active to loss of voltage to reactive:

$$
k=\frac{\Delta U_{a}}{\Delta U_{r}}=\frac{I_{n} \cdot R \cdot \cos \varphi}{I_{n} \cdot X \cdot \sin \varphi}=\frac{r_{t} \cdot \cos \varphi}{x_{t} \cdot \sin \varphi},
$$

given that the slope of the characteristic is calculated from the expression, $\%$ : 


$$
k_{s t}=\frac{\Delta U}{U_{s . p .}} \cdot 100,
$$

where $U_{\text {s.p. }}-$ voltage set point, $\mathrm{V} ; \Delta U-$ the maximum change in voltage when you turn on VAR generator, V:

$$
\Delta U=I_{n} \cdot x_{c}
$$

where $I_{n}$ - rated current VAR generator, A; $x_{\mathrm{c}}$ - resistance from the source to the connection point of the var generator, Ohm.

Thus, the slope of the VAR generator excluding voltage losses on the active component of the traction load is determined from the expression, $\%$ :

$$
k_{s t}=\frac{k \cdot I_{n} \cdot x_{c}}{U_{s . p .}} \cdot 100 .
$$

Based on the results of the analysis, figure 4 presents an algorithm for selecting the current ampere characteristics for both types of VAR generator used in the traction power supply system, the control algorithm of which is based on the measurement of voltage at the connection point.

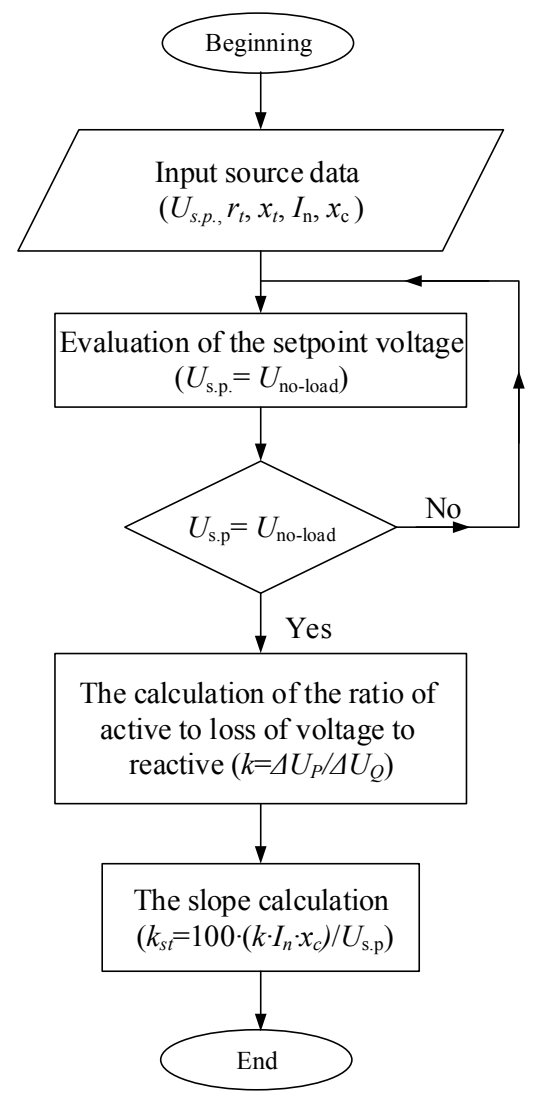

Fig. 4. The algorithm for selecting the volt ampere characteristics 


\section{Discussion}

The following is a selection of the slope of the working characteristics for STATCOM installed on the station Pankrushikha.

Source data:

$I_{n}=229 \mathrm{~A} ; x_{\mathrm{c}}=5.4 \mathrm{Ohm} ; U_{n}=27500 \mathrm{~V} ; U_{\text {s.p. }}=28500 \mathrm{~V}$; normal power supply parallel circuit. Type of suspension PBSM-70+MF 100+4P65; $r_{t}=0.111 \mathrm{Ohm} / \mathrm{km}, x_{t}=0.288$ $\mathrm{Ohm} / \mathrm{km}$.

We calculate the ratio of active voltage losses to reactive:

$$
k=\frac{0.111 \cdot \cos 35}{0.288 \cdot \sin 35}=0.55 \text {. }
$$

Next, the formula (9) determine the slope of the performance, $\%$ :

$$
k_{s t}=\frac{0.55 \cdot 229 \cdot 5.4}{28500} \cdot 100=2.39 /
$$

The results of the work were implemented at this facility, which reduced the electric power losses in the traction power supply system by $0.11 \%$.

\section{Conclusions}

The choice of the current-voltage characteristics for zone must be performed based on the local feasibility conditions. The voltage set point in the proposed method is selected based on the reduction of the VAR generator operation time, while ensuring the capacity.

The choice of inclination is based on the exclusion of overcompensation of reactive power, by eliminating the loss of voltage on the active component of the traction load.

The presented method allows to reduce electricity losses in the traction network, increasing the efficiency of the traction power supply system.

\section{References}

1. D. Shetty, Procedia Energy, 117, 543-550 doi.org/10.1016/j.egypro.2017.05.143

2. T. Eswaran, Journal of Applied Research and Technology, 15, 173-189 (2017) doi.org/10.1016/j.jart.2017.01.011

3. D. Shetty, Procedia Energy, 117, 551-558 doi.org/10.1016/j.egypro.2017.05.145

4. J. Olamaei, Procedia Energy, 14, 298-303 doi.org/10.1016/j.egypro.2011.12.933

5. I. Hussain, International Journal of Electrical Power \& Energy Systems, 93, 238-252 (2017) https://doi.org/10.1016/j.ijepes.2017.06.005

6. B. Singh, Journal of Electrical Systems and Information Technology, 5, 388-426 (2018) doi.org/10.1016/j.jesit.2018.02.005

7. B. Sravan Kumar, Procedia Computer Science, 92, 42-47 (2016) doi.org/10.1016/j.procs.2016.07.321

8. H. Guillardi Júnior, HardwareX, 5, e00049 (2019) doi.org/10.1016/j.ohx.2018.e00049 
9. W. Liu, Procedia Energy, https://doi.org/10.1016/j.egypro.2012.02.125

17, $\quad 483-491$

(2012)

10. B. Singh, Energy Reports, 4, 418-434 (2018) doi.org/10.1016/j.egyr.2018.07.004

11. E. Barrios-Martínez, Journal of Applied Research and Technology, 15, 36-44 (2017) doi.org/10.1016/j.jart.2017.01.001 